\title{
INFANTILE HEMANGIOENDOTHELIOMA OF LIVER: CASE REPORT
}

\author{
Radhika Krishna 0. $\mathrm{H}^{1}$, Geetha $\mathrm{K}^{2}$, Ramani Malleboyina3 ${ }^{3}$, Ravi Kumar P4, Ramesh Reddy $\mathrm{K}^{5}$
}

\section{HOW TO CITE THIS ARTICLE:}

Radhika Krishna O. H, Geetha K, Ramani Malleboyina, Ravi Kumar P, Ramesh Reddy K. "Infantile Hemangioendothelioma of Liver: Case Report". Journal of Evolution of Medical and Dental Sciences 2015; Vol. 4, Issue 71, September 03; Page: 12463-12467, DOI: 10.14260/jemds/2015/1794

ABSTRACT: Infantile Hemangioendothelioma of the liver is an uncommon tumor. Two subtypes have been described. Type1 has recognizable but irregularly dilated vascular spaces in a fibromyxomatous stroma. Type 2 is described as having a more aggressive histology. It is marked by poorly formed and anatomising channels with papillae lined by atypical endothelial cells and is potentially malignant. Clinical presentation is variable, hepatomegaly or abdominal mass, some hematological abnormalities may be seen. In laboratory investigation, or lesion may be asymptomatic and discovered incidentally. We report a case of 45 day old female child who presented with abdominal distension. CT abdomen showed hypoattenuating mass in the left lobe of the liver along with specks of calcification.. The mass was excised and had large areas of gritty calcification simulating a teratoma. however histopathological diagnosis of infantile hemangioendothelioma type I of liver was made. Hemangioendothelioma of the liver has been reported as most common benign symptomatic vascular tumor of the liver in infancy.

KEYWORDS: Hemangioendothelioma, Liver, Vascular Tumor, Infant, Teratoma.

INTRODUCTION: Infantile hemangioendothelioma is the third most common hepatic tumor in children forming $12 \%$ of the hepatic tumors.[1] Two sub types have been described based on tumor size and vascularity.[2] Solitary lesions are more common than multiple lesions.[1] The present case is a 45 day old female child who presented with abdominal distension and solitary mass in left hypochondrium.

CASE REPORT: 45 days old female patient presented with distension of abdomen, respiratory distress and regurgitation of milk. Antenatal history was uneventful. Birth history was normal. Parents noticed distension of abdomen with dilated veins at the age of 21 days. The mass was noted in left hypochondrium which gradually increased in size.

Palpation revealed a non-pulsatile mass in the left hypochondrium. USG abdomen showed a large heterogeneous mass in the left renal area $89 \times 5 \mathrm{~mm}$ size with specks of hyperechogenecity, left kidney was not separately seen and diagnosis of nephroblastoma was suggested. CECT abdomen revealed large peripherally enhancing mass $84 \times 52 \times 87 \mathrm{~mm}$ mass arising from left lobe of liver extending from left hypochondrium to left iliac fossa with specks of hyperdense areas suggestive of calcifications were noted [Figure 1]. A differential diagnosis of hepatoblastoma, teratoma, neuroblastoma or exophytic hemangioendothelioma of the liver were given on radiological examination. All routine investigations were done. Peripheral blood smear shows normocytic normochromic picture with normal white cell count but Platelet count was 40,000 cells/mm suggesting thrombocytopenia. Liver Function Tests were within normal limits. Serum AFP levels and catecholamine levels were normal.

Wide range of differential diagnosis was given including malignancy by clinical and radiological examination. Surgical exploration was performed and well encapsulated mass was 
excised from the left lobe of the liver and sent for Histopathological examination. Gross examination revealed $8 \times 8.5 \mathrm{~cm}$ well encapsulated heterogeneous mass with solid and cystic areas along with calcified foci. Tumor was looking grossly like a teratoma. [Figure 2]. Microscopy revealed vascular channels lined by continuous layer of plump endothelial cells in supporting fibrous stroma [Figure 3], Foci of fibrous scarring, specks of calcification and areas of extra medullary hematopoiesis were noted [Figure 4]. Foci of organized haemorrhage were also seen. Mitotic activity was found to be low. Histopathological features were in favour of infantile hemangioendothelioma of the liver type- 1.

DISCUSSION: Infantile hemangioendothelioma is a rare tumor found almost exclusively in children before 6 months of age. It is a highly cellular hemangioma that may appear as solitary or multiple nodules that may be associated with hemangiomas of other sites particularly skin. A female predominance has been noted as is the present case. Tumor may be asymptomatic \& discovered incidentally or with hepatomegaly or as a palpable upper abdominal mass. In present case the child presented with distension of abdomen with prominent vessels.

Hematologic abnormalities like leukocytosis, anemia and thrombocytosis or thrombocytopenia may be seen. ${ }^{[3]}$ The peripheral smear revealed thrombocytopenia in our case.

On imaging they appear as complex mostly solid hepatic lesion with variable hypo and hyper echoic texture. ${ }^{[4]}$ In our case ultrasound abdomen showed a large heterogeneous mass with specks of hyperechogenecity. CECT abdomen revealed large peripherally enhancing mass arising from left lobe of liver with hyperdense areas suggesting calcific foci [Figure 1].

Grossly the tumor shows variegated appearance, grey tan and gelatinous appearance with cystic and necrotic areas.[5] In our case, the tumor was well circumscribed, encapsulated mass with solid and cystic areas [Figure 2].

In 1971 Dehner and Ishak have proposed classifying infantile hemangioendothelioma into two histologic types: Type I IHHE also referred to as benign hemangioendothelioma or hepatic infantile hemangioma is used to describe the more common variant of the two and is formed by capillary sized vessels lined by a single layer of somewhat plump but bland endothelial cells with rare mitotic figures.

Type II IHHE contains vessels with pleomorphic endothelial cells and was often considered to be the same lesions as angiosarcoma.[3] Type II IHHE has also been referred to as epithelioid angiosarcoma and kaposiform angiosarcoma in literature.

Nord et al.,[6] have reported such a case affected by type II IHHE with cutaneous hemangiomas. Microscopy of present case correlated with type I IHHE. The diagnosis of infantile hemangioendothelioma should be considered when the patient is younger than six months of age by specific histological and radiological findings. Most important differential diagnosis to infantile hemangioendothelioma is hepatoblastoma which is a malignant embryonic tumor seen in infants and children. ${ }^{[2,7]}$ Other benign lesions that have to be differentiated from infantile hemangioendothelioma histologically are mesenchymal hamartomas.

Patients with infantile hemangioendothelioma have usually excellent prognosis and spontaneous regression is known to occur after first year of life. And children may die of associated complications such as severe heart failure or rupture.[5] Treatment is determined on the basis of tumor size and severity of symptoms like CHF, AV shunting or coagulopathy. Surgical resection is indicated if life threatening symptoms are present or if the mass cannot be distinguished from a malignant tumor radiologically. ${ }^{[4]}$ 
CONCLUSION: We have reported a case of infantile hemangioendothelioma with multiple specks of calcification were noted in the CT scan and a wide differential diagnosis was given including malignancy. Therefore understanding of the clinical presentation and detailed histopathology of types of infantile hemangioendothelioma of liver is essential for diagnosis.

ACKNOWLEDGEMENT: Authors acknowledge the immense help received from the scholars whose articles are cited and included in references of this manuscript. The authors are also grateful to authors/editors/publishers of all those articles, journals and books from where the literature for this article has been reviewed and discussed.

\section{REFERENCES:}

1. Selby DM, Stocker JT, Waclawiw MA, Hitchcock CL, Ishak KG. Infantile hemangioendothelioma of the liver. Hepatology. 1994; 20(1): 39-45.

2. Zenge JP, Fenton L, Lovell MA, Grover TR. Case report: infantile hemangioendothelioma. CurrOpin Pediatr. 2002; 14: 99-102.

3. Zhanz Zhang, Hui-Jiao Chen, Wen-JuanYang, Hong Bu, Bing Wei, Xiao-Yu Long, et al. Infantile hepatic hemangioendothelioma: A clinico pathological study in a Chinese population. World J of Gastroenterol. 2010; 16(36): 4549-4557.

4. Ingram JD, Yerushalmi B, Connell J, Karrer FM, Tyson RW, Sokol RJ. Hepatoblastoma in a neonate: a hypervascular presentation mimicking hemangioendothelioma. Pediatric Radiol. 2000; 30: 794-797.

5. Suh YL, Cho KJ, Chi JG, Park KW. Infantile hemangioendothelioma of liver - a case report. J Korean Med Sci. 1987; 2(3): 195-200.

6. K.M. Nord, J. Kandel, J.H. Lefkowitch, S.J. Lobritto, K.D. Morel, P.E. North, M.C. Garzon, Multiple cutaneous infantile hemangiomas associated with hepatic angiosarcoma: case report and review of the literature, Pediatrics 118 (3) (2006) e907-e913 Epub 2006 Jul 31. Review. Erratum in: Pediatrics. 2007 Jun; 119(6): 1271.

7. Keslar PJ, Buck JL, Selby DM. Infantile hemangioendothelioma of the liver revisited. Radio Graphics 1993; 13: 657-667.

Abbreviations: IHHE - Infantile Hepatic Hemangioendothelioma

Fig. 1: CT scan showing heterogeneous mass with specks of hyperechogenecity

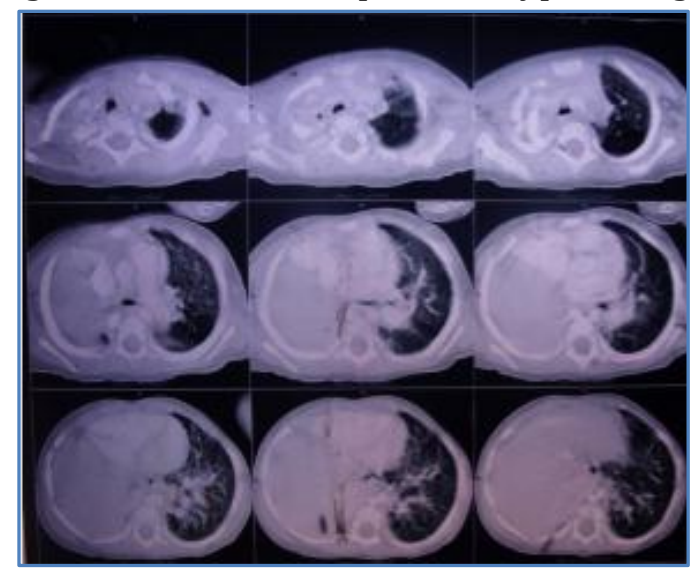

Fig. 1 


\section{CASE REPORT}

Fig. 2: Photograph showing single grey tan well circumscribed nodular mass with variegated appearance. Cut section showing calcified areas simulating teratoma.

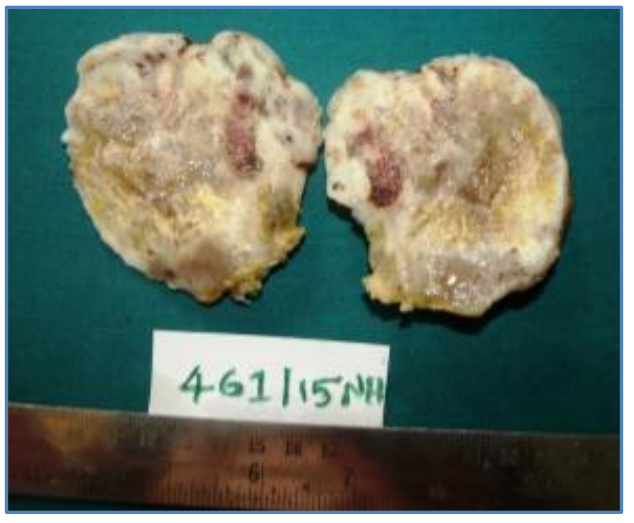

Fig. 2

Fig. 3: Micrograph showing vascular spaces lined by endothelial cells with well-preserved bile ductules.

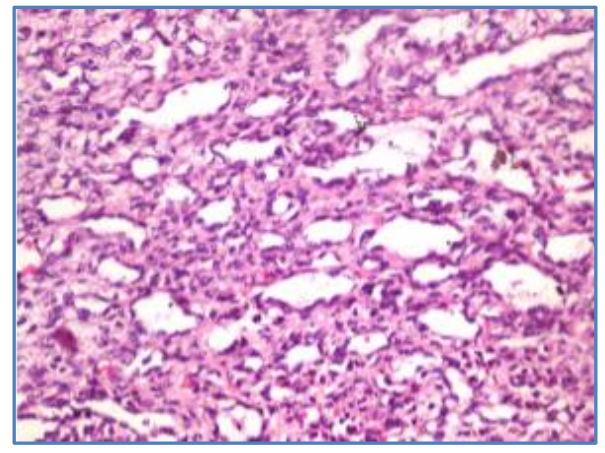

Fig. 3

Fig. 4: Micrograph showing areas of calcifications.

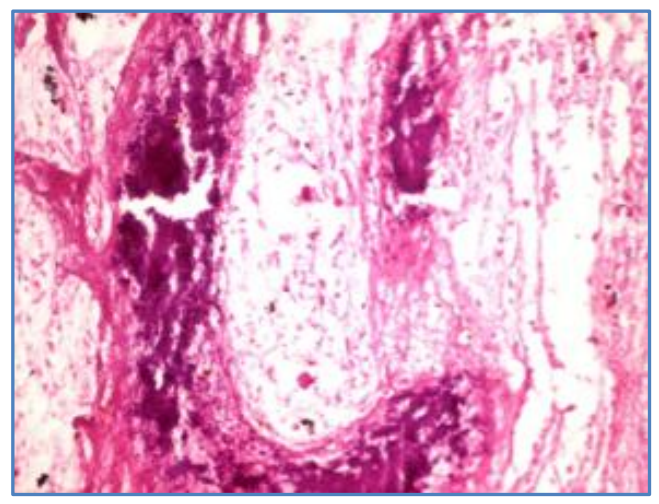

Fig. 4 


\section{CASE REPORT}

\section{AUTHORS:}

1. Radhika Krishna O. H.

2. Geetha K.

3. Ramani Malleboyina

4. Ravi Kumar P.

5. Ramesh Reddy K.

\section{PARTICULARS OF CONTRIBUTORS:}

1. Assistant Professor, Department of Pathology, Niloufer Hospital, Red Hills, Hyderabad.

2. Assistant Professor, Department of Pathology, Niloufer Hospital, Red Hills, Hyderabad.

3. Professor, Department of Pathology, Niloufer Hospital, Red Hills, Hyderabad.

FINANCIAL OR OTHER COMPETING INTERESTS: None
4. Post Graduate, Department of Pathology, Niloufer Hospital, Red Hills, Hyderabad.

5. Professor, Department of Pediatric Surgery, Niloufer Hospital, Red Hills, Hyderabad.

\section{NAME ADDRESS EMAIL ID OF THE}

\section{CORRESPONDING AUTHOR:}

Dr. Radhika Krishna. O. H, Department of Pathology, Niloufer Hospital, Red Hills, Hyderabad-500004.

E-mail: othulururadhika@yahoo.co.in

Date of Submission: 31/07/2015. Date of Peer Review: 01/08/2015. Date of Acceptance: 28/08/2015. Date of Publishing: 03/09/2015. 